\title{
Globalização e desenvolvimento baseado em matérias-primas: o caso da indústria do alumínio
}

Paul Ciccantell - Professor do Departamento de Sociologia da Western Michigan University, EUA.

Resumo

Partindo da noção de que a globalização é um processo longo, que exibe características distintas, em diferentes indústrias e em diferentes períodos, o artigo examina a natureza mutável do processo de globalização na indústria de alumínio, ratifica a sua condição de uma das indústrias verdadeiramente globais e analisa a sua trajetória, desde a criação da estrutura de oligopólio, nos primeiros anos desta indústria, até as mudanças ocorridas no decorrer do século XX.

\section{Abstract}

From the notion that globalization is a long process, which shows distinct characteristics, in different industries and in different periods, the article examines the mutable nature of the globalization process in the aluminum industry. This article confirms the aluminum industry as one of the most truly global industries and analyses its trajectory, since the creation of the oligopoly structure, in the first years of this industry, until the changes that happened in the $20^{\text {th }}$ century.

\section{Palavras-chave}

globalização, indústria global, alumínio, bauxita, alumina

\section{Keywords}

globalization, global industry, aluminium, bauxite, alumina 


\section{A ESPECIFICIDADE HISTÓRICA E SETORIAL DA GLOBALI- ZAÇÃO}

A atual análise, tanto popular quanto acadêmica, do processo de globalização presume, freqüentemente, que se trata de um fenômeno novo, que opera da mesma maneira em todos os setores da economia. Este artigo defende a idéia de que exatamente o oposto é verdadeiro: a globalização é um longo processo, que exibe características distintas, em diferentes indústrias e em diferentes períodos. A estratégia analítica para abordar aqui esse processo baseia-se historicamente no setor de matérias-primas e, em particular, na indústria do alumínio, uma das pioneiras do processo de globalização. Este trabalho examina a natureza mutável do processo de globalização na indústria do alumínio, enfatizando a articulação de estratégias competitivas de empresas globalizantes e as estratégias de desenvolvimento econômico dos governos nacionais.

Neste estudo, identificamos quatro fases distintas da globalização, desde o final do século XIX. Examinaremos aqui a articulação dessas fases com a evolução das estratégias competitivas desenvolvidas pelas corporações transnacionais (CTN) e as três maiores estratégias de desenvolvimento empregadas pelos estados periféricos e semiperiféricos a fim de promover o crescimento econômico, a industrialização para substituição de importações (ISI), a industrialização para aumento de exportação (IAE) e a reestruturação econômica. As estratégias de desenvolvimento dos estados, em nações periféricas e semiperiféricas, são formuladas e implementadas no contexto desse processo mais amplo e também no contexto das estratégias de empresas e estados do centro, a fim de que eles possam atingir seus próprios objetivos no contexto da globalização.

Essa estratégia analítica torna possível colocar a globalização dentro de seu contexto a longo prazo, uma vez que, há um século, ela tem estado presente em algumas indústrias, incluindo a do alumínio. Essa estratégia também torna claro aquilo que é realmente novo nas mais recentes fases da globalização, particularmente a mudança para novas formas de cooperação e competição entre empresas e o papel da reestruturação econômica e da privatização em toda a economia mundial. Finalmente, essa estratégia analítica, ao voltar sua atenção para as conseqüências dessa nova fase, com relação a uma determinada indústria, permitirá um entendimento mais profundo do significado da fase mais recente da globalização para as empresas, as economias nacionais e as pessoas. 


\section{GLOBALIZAÇÃO E ESTRATÉGIAS DE DESENVOLVIMENTO}

O ponto de partida para esta análise é o conceito, amplamente utilizado, de globalização: "a intensificação das relações econômicas, políticas, sociais e culturais além das fronteiras" (HOLM; SORENSON, 1995, p. 4). Para muitos analistas, um elemento central nesse processo é a compressão do tempo e do espaço: a movimentação de bens que durava meses pode acontecer hoje em questão de dias ou mesmo horas; cidades distantes são ligadas por vôos freqüentes e a informação ocorre de maneira virtualmente instantânea até mesmo em locais remotos.

Em um sentido mais amplo, a globalização é uma característica inerente à economia capitalista mundial, com efeitos transnacionais largos e profundos, incorporando, progressivamente, territórios e grupos sociais nessa economia. A economia política clássica de Adam Smith, David Ricardo e Karl Marx examinou várias dimensões desse processo, inclusive o comércio, o imperialismo e a contribuição das regiões periféricas para o desenvolvimento dos países centrais, uma tradição analítica ampliada pelos analistas da dependência, pela teoria dos sistemas mundiais e por outros analistas da economia política. Entretanto, a natureza da globalização modificou-se dramaticamente ao longo do século passado, pois empresas globais e redes de produção emergiram desde o final do século XIX.

A primeira fase da globalização, entre o final do século XIX e o início do século XX, teve três componentes principais. O primeiro foi a busca constante de novos mercados para produtos industriais do centro em outras partes do mundo, um processo que começou como um projeto imperialista nos séculos XV e XVI, quando a economia mundial capitalista estava em emergência (WALLERSTEIN 1974, 1989). O segundo componente foi a busca mais intensiva de matérias-primas, em regiões cada vez mais remotas, para consumo das indústrias do centro, em razão de um rápido esgotamento dessas matérias-primas no âmbito doméstico, causado pela industrialização ocorrida na Europa e América do Norte. A extração de matérias-primas para exportação aos países do centro já vivera uma longa história, porém a rápida expansão da indústria pesada (ferro, aço, carvão, cobre, petróleo e alumínio), ao final do século XIX, tornou essencial essa busca global para o crescimento econômico do centro. O terceiro componente dessa fase da globalização foi o grande papel desempenhado pelas empresas, cujas operações estavam tornando-se cada vez mais globais, no âmbito das corporações transnacionais (HYMER, 1979). Nos pro- 
dutos de consumo e, particularmente, nas indústrias de matérias-primas, as corporações transnacionais tornaram-se os principais atores do processo de globalização, deslocando, gradualmente, os esforços imperialistas praticados ao longo de várias décadas, desde o final do século XIX até meados do século XX.

A segunda fase da globalização, ocorrida durante o século passado, começou com o fim da II Guerra Mundial e estendeu-se durante o processo de descolonização que se seguiu. A hegemonia econômica e política dos EUA, a partir do final da década de 40 até o final da década de 60, foi internacionalmente manifestada pelas empresas transnacionais, baseadas naquele país. As principais estratégias utilizadas por essas CTN, durante esse período, foram: expandir-se globalmente para vender produtos made in USA em outros países; investir nas instalações da produção nacional para suprir a demanda dos mercados locais, quando necessário, repatriando os lucros para as matrizes nos Estados Unidos; exportar produtos feitos nessas fábricas para os EUA; finalmente, exportar matérias-primas para as indústrias norte-americanas (BARNET; MULLER, 1974; HYMER, 1979; JENKINS, 1987; CHASE-DUNN, 1989).

Entre essas características, a frase "quando necessário" é particularmente importante. A mudança mais significativa durante essa fase da globalização foi a vontade e a habilidade cada vez maiores dos governos em todo o mundo de forçar as CNT norte-americanas e outras a investir localmente nas instalações da Industrialização para Substituição de Importações (ISI). O acesso aos mercados locais era freqüentemente condicionado ao investimento na produção local; em países com mercados domésticos amplos e em crescimento, como o Brasil, esses esforços eram bastante eficazes. Conforme habilmente demonstrou Peter Evans (1979), uma aliança tripartite entre as CNT, o capital local e o governo brasileiro atuou em conjunto para promover o desenvolvimento industrial do Brasil, transformando o país em uma das maiores nações industriais do mundo, por volta da década de 70. Um processo de certa forma semelhante aconteceu em muitos outros países, entre os que atualmente são chamados Países Emergentes Industrializados (PEI), geralmente com ênfase na promoção das exportações durante as décadas de 50 e 60. Muitos outros países periféricos fizeram esforços de ISI durante as décadas de 50 e 60, normalmente, com menos sucesso. Nas indústrias de matérias-primas, no período pós-guerra, especialmente a partir do final da década de 60 até o início da década de 80, a riqueza em matérias-primas representava um caminho para o desenvolvimento, buscado e seguido por 
muitos países periféricos. Baseados no modelo de efeitos proposto por Hirschman (1958) e na lógica dos pólos de crescimento (PERROUX, 1955; BUNKER, 1989), diversos países periféricos seguiram as prescrições daquilo que tem sido chamado de industrialização baseada em recursos (ROOMER, 1979; AUTY, 1990). Para alguns países, esta foi a principal contribuição para a mobilidade para cima na estrutura social global, movimentando-se da periferia para a semiperiferia da economia mundial (CICCANTELL, 1994).

Entretanto, conforme discutido por Cox (1996), uma importante mudança qualitativa na natureza da globalização surgiu em meados da década de 70, marcando a terceira fase da globalização. A questão central agora era: qual a diferença entre essa fase da interconectividade global e os períodos anteriores? Foram identificadas diversas características distintas dessa fase da globalização, como se verá a seguir.

1. Tecnologias mais rápidas e baratas de transporte permitem ligações sistêmicas de empresas e mercados no mundo inteiro, incluindo transportadoras de matérias-primas em grande escala e remessas conteinerizadas e intermodalizadas de produtos manufaturados (BUNKER; CICCANTELL, 1995; SASSEN, 1996). Essas tecnologias têm raízes na fase anterior de globalização, mais notadamente na expansão da produção industrial japonesa, que enfrentava o duplo problema de como baixar o custo de importação de grandes volumes de matérias-primas (BUNKER; CICCANTELL, 1995) e como exportar produtos a custo competitivo para os mercados europeus e norte-americanos. O emprego dessas tecnologias e sistemas de transporte pelos países centrais forçou, por sua vez, outros países a desenvolver infra-estruturas compatíveis de transporte, para que permanecessem competitivos na economia mundial, cada vez mais integrada.

2. Tecnologias e infra-estruturas de comunicação melhoradas permitem às empresas coordenar e controlar operações espalhadas em dezenas de países (SASSEN, 1996). Assim como aconteceu à infra-estrutura de transporte, as comunicações estavam no estágio inicial de desenvolvimento durante as décadas de 50 e 60, o que permitiu a criação de Zonas de Processamento de Exportações e de outras áreas de operação de montagem com baixos salários, principalmente na Ásia (FROBEL; HEINRICH; KREYE, 1980; APPELBAUM; SMITH; CHRISTERSON, 1994)). Desde meados da década de 70, as infra-estruturas de comunicação tornaram-se outro ingrediente essencial para manter a competitividade na economia mundial. 
3. Corporações transnacionais de âmbito global estão desempenhando um papel econômico cada vez maior em todo o mundo, sendo que uma grande parte do comércio mundial está tomando a forma de transferências intra-empresariais, freqüentemente em ações coordenadas entre vários parceiros (PORTER, 1990). O crescimento do comércio mundial por meio das transferências intra-empresariais começou, seriamente, no final do século XIX. Desde meados da década de 70, esse processo tem se intensificado e se tornado mais complexo, em grande parte sob a forma de transferências entre joint ventures, parceiros em contratos de longo prazo e outros mecanismos que ligam as empresas, em detrimento das formas de transferência efetuadas entre subsidiárias e suas matrizes.

4. As estratégias de desenvolvimento dos estados periféricos e semiperiféricos migraram para a promoção das exportações mediante políticas de Industrialização para Aumento de Exportação (IAE), desde meados da década de 70. Esses estados continuaram a desempenhar um grande papel, direto ou indireto, em suas economias nacionais, porém os objetivos da estratégia de desenvolvimento migraram do fornecimento aos mercados internos para a exportação aos mercados mundiais, a fim de obter divisas e pagar as dívidas externas e também para aumentar a produtividade interna, expondo suas empresas aos mercados mundiais, altamente competitivos.

Em meados da década de 80, começou uma quarta fase da globalização, marcada pela maior intensificação dos processos da terceira fase em combinação com mais dois novos elementos. Primeiro, uma ampla tendência à redução das barreiras comerciais, tanto na esfera global como na regional, que se expandiu rapidamente, incluindo o Acordo Geral sobre Tarifas e Comércio (GATT) e a Organização Mundial do Comércio (OMC), no âmbito global, e o Acordo de Livre Comércio da América do Norte (ALCA) e a União Européia (UE), no âmbito regional (COGGINS; WILKINSON, 1981). Esses acordos comerciais globais e regionais, de certo modo conflitantes, estão aproximando os elos entre as economias nacionais. Segundo, as estratégias de desenvolvimento dos estados por meio da economia mundial passaram para um projeto neoliberal de liberalização econômica, desde meados da década de 80. Para as nações fora do eixo central, a amortização da dívida, por volta da década de 80, começou a exigir a promoção das exportações, a restrição da demanda interna, a redução do papel econômico do Estado e a abertura para os investimentos estrangeiros (COX, 1996, p. 22). Assim, o papel dos países periféricos e semiperiféricos mudou dramaticamente desde meados 
daquela década. O papel econômico desses países, principalmente como forças propulsoras das estratégias de desenvolvimento, começou a sofrer erosão, ficando restrito apenas ao de promotores do território nacional como um local para investimentos estrangeiros, competindo com outras jurisdições políticas, em todo o mundo, assim como o papel de provedor de um arcabouço de governabilidade para apoiar essa nova fase da globalização (SASSEN, 1996, p. 41; 46). Um processo similar também foi iniciado nos países centrais, durante esse período, questionando o acordo capital-trabalho (BOWELS; GINTIS, 1998) e a solução do bem-estar social proposta pelos governos para o problema da década de 30.

Essas fases da globalização e sua relação com as estratégias de desenvolvimento dos estados suscitaram um conjunto geral de questionamentos, ligados entre si, sobre o processo de globalização, desde o final do século XIX:

a) Quais são as estratégias e conseqüências para as empresas globalizantes?

b) Quais são as estratégias e conseqüências para os países centrais?

c) Quais são as conseqüências para as regiões centrais, incluindo as economias nacionais, o trabalho, outros capitais, outros grupos sociais e ecossistemas?

d) Quais são as estratégias e conseqüências para as empresas periféricas e semiperiféricas, envolvidas nas indústrias globais?

e) Quais são as estratégias e conseqüências para os estados periféricos e semiperiféricos?

f) Quais são as conseqüências para as regiões periféricas e semiperiféricas, incluindo economias nacionais, trabalho, outros capitais, outros grupos sociais e ecossistemas?

Deste ponto em diante, far-se-á um primeiro corte analítico nesses assuntos interligados, focalizando-se uma indústria global: a do alumínio. Essa indústria começou a globalizar-se logo após seu nascimento na década de 80 do século XIX, buscando matérias-primas que se estavam rapidamente esgotando nas nações centrais e competindo por novos mercados em muitos países e regiões do mundo. Esta abordagem de uma indústria específica abre uma janela analítica sobre as conseqüências da globalização e inaugura um bloco de construção para uma análise mais ampla das fases e conseqüências dessa mesma globalização. 


\section{A GEOGRAFIA DA GLOBALIZAÇÃO DA INDÚSTRIA DO ALU- MÍNIO}

A indústria do alumínio foi uma das primeiras indústrias verdadeiramente globais e uma pioneira nesse processo. A indústria do alumínio foi estabelecida nas décadas de 80 e 90 do século XIX, por empresas da Europa e dos EUA. Sua origem deve-se ao desenvolvimento contemporâneo de tecnologias que eram capazes de produzir alumínio puro a partir da bauxita (a forma de minério que ocorria mais comumente), a um custo competitivo. Essas empresas e seus clientes desenvolveram uma variedade de usos para esse material leve, forte e maleável, que recentemente havia se tornado disponível, mais precisamente para o transporte, armamentos e bens de consumo, durante as primeiras três décadas de existência da indústria. Esses usos no transporte e em armamentos tornaram claro para os governos nacionais da Europa o valor estratégico da indústria do alumínio, o que resultou no apoio governamental a empresas nacionais de fabricação de alumínio. A competição existente no final do século XIX e início do século XX era muitas vezes intensa entre esses monopólios nacionais, subsidiados pelo governo, bem como entre essas grandes empresas e diversas companhias menores, recém-chegadas aos mercados dos EUA e da Europa. Esse conflito foi eventualmente resolvido com a criação de um oligopólio de quatro empresas. Mais tarde, após a intervenção do governo norte-americano, na II Guerra Mundial, para aumentar a produção bélica, foi criado um oligopólio de seis empresas que dividiam o mercado mundial de alumínio entre si, por meio de mecanismos de cooperação formal e informal, incluindo cartéis e um sistema de liderança de preços e restrição da produção (WALLACE, 1937; MARLIO, 1947; CARR, 1952; SMITH, 1988). Esse sistema persistiu desde as primeiras décadas do século $X X$ até a década de 70 (CICCANTELL, 1994). A competição global pelos mercados e, por vezes, a extensa cooperação entre as empresas, características principais do processo de globalização, têm sido a marca registrada da indústria do alumínio, desde suas origens, durante a primeira fase da globalização, no final do século XIX.

A indústria do alumínio foi globalizadora também em uma outra dimensão, desde os primeiros anos de sua fundação. Fontes domésticas de minério de bauxita e locais com grande potencial hidrelétrico (a fundição do alumínio é uma das indústrias mais intensivas em consumo de energia do mundo, fazendo com que a energia hidrelétrica, de baixo custo, seja a mais importante fonte de energia para a indústria, ao longo de sua história) foram rapidamente utilizados e esgotados por volta do 
início do século XX. A busca de matéria-prima estrangeira começou na virada do século, incluindo a expansão para regiões periféricas, ricas em matéria-prima, como o Canadá e a Noruega, em busca de usinas hidrelétricas para fornecer energia às fundições de alumínio e do desenvolvimento de minas de bauxita nas então Guianas Inglesa e Holandesa, na América do Sul, e na Índia, todas produzindo para exportação aos países centrais da Europa Ocidental e dos Estados Unidos (BUNKER; CICCANTELL, 1994; WALLACE，1937; MARLIO, 1947; CARR, 1952; SMITH, 1988). O esgotamento das matérias-primas no eixo central levou à criação de empresas globais de fabricação de alumínio, com fontes de matéria-prima em todo o mundo, outra marca registrada da primeira fase da globalização. As mais importantes empresas de alumínio (membros do oligopólio de quatro e mais tarde seis empresas) têm sido globais há mais de um século, criando estratégias de mercado e matéria-prima que hoje se espalham por dezenas de países (Tabela 1). Essas maiores empresas de alumínio, juntamente com diversas empresas ligadas a outras indústrias de matérias-primas, foram as pioneiras do processo de globalização.

Tabela 1: Produção mundial de bauxita (em toneladas)

\begin{tabular}{|c|c|c|c|c|}
\hline Ano & $\begin{array}{c}\text { Produção mundial } \\
\text { total de bauxita }\end{array}$ & $\begin{array}{c}\text { Aumento } \\
\text { percentual }\end{array}$ & $\begin{array}{c}\text { Número de } \\
\text { países }\end{array}$ & $\begin{array}{c}\text { Parte dos três } \\
\text { maiores países }\end{array}$ \\
\hline 1900 & 89.000 & & 3 & $100 \%$ \\
\hline 1910 & 350.227 & $294 \%$ & 5 & $99 \%$ \\
\hline 1920 & 901.000 & $157 \%$ & 12 & $92 \%$ \\
\hline 1930 & 1.629 .000 & $81 \%$ & 14 & $74 \%$ \\
\hline 1940 & 4.459 .300 & $174 \%$ & 21 & $42 \%$ \\
\hline 1950 & 8.160 .000 & $83 \%$ & 20 & $62 \%$ \\
\hline 1960 & 26.479 .000 & $225 \%$ & 27 & $44 \%$ \\
\hline 1970 & 57.784 .000 & $118 \%$ & 28 & $47 \%$ \\
\hline 1980 & 89.220 .000 & $54 \%$ & 28 & $57 \%$ \\
\hline 1990 & 109.118 .000 & $22 \%$ & 27 & $62 \%$ \\
\hline 1995 & 109.000 .000 & $0 \%$ & 28 & $60 \%$ \\
\hline 1997 & 115.000 .000 & $5,5 \%$ & & \\
\hline
\end{tabular}

Fontes: USBM (vários anos); Minerals Yearbook; Metallgesellschaft (vários anos); Metallstatistik. UN (vários anos); World Trade Tables.

O número de países envolvidos no estágio da mineração de bauxita da indústria de alumínio cresceu rapidamente durante as seis primeiras décadas. O aumento do número de países produtores de bauxita, em 1960, que era de 27, próximo ao pico, coincidiu com outra importante mudança na geografia da produção dessa matéria-prima: 
a concentração da produção em três países começou a crescer paulatinamente, chegando novamente a 62\%, em 1990. Essa crescente concentração da produção deveria favorecer, com base nas características das indústrias de matérias-primas, um controle maior do oligopólio na indústria e, por outro lado, um poder maior de mercado nas mãos dos proprietários das matérias-primas (BARHAM; BUNKER; O'HEARN, 1994). A previsão de um maior poder de mercado para os proprietários de matéria-prima foi inicialmente ventilada pela formação da Associação Internacional da Bauxita (AIB), na década de 70, que se esforçou para aumentar os impostos e royalties sobre a produção de bauxita a fim de obter mais rendimentos desse minério (STEPHENS; STEPHENS, 1985). Entretanto, esse esforço foi dramaticamente cortado pelas ações da política nacional e estadual do maior produtor mundial de bauxita, a Austrália, cujo sistema federal descentralizado e seu duplo status de produtor de matéria-prima em grande escala e de país industrializado resultaram em uma omissão para agir em prol de um aumento de preço da bauxita, mediante maiores impostos e royalties. A não participação do maior produtor mundial de bauxita limitou enormemente a eficácia da AIB e evitou a passagem, em larga escala, do poder de mercado das empresas para os detentores da matéria-prima e, eventualmente, contribuiu para a derrocada da AIB. A previsão de aumento do controle do oligopólio na indústria também não ocorreu, devido às mudanças na estrutura do estágio de fundição do alumínio, bem como na indústria como um todo, o que discutiremos a seguir.

A mineração de bauxita também passou dos países industrializados para os países em desenvolvimento, no decorrer de sua história. Em 1900, as três nações produtoras eram os Estados Unidos, a França e a Grã-Bretanha. Por volta de 1910, a Índia começou sua produção. Em 1920, a Guiana Inglesa havia começado a produzir bauxita e, por volta de 1930, duas outras colônias européias, a Guiana Holandesa (Suriname) e a Austrália haviam entrado no ranking das nações produtoras. O Brasil, a Costa do Ouro (Gana), uma colônia britânica, e a África Ocidental Francesa (Guiné) começaram a produzir bauxita na década de 50, e a Jamaica passou a ser um importante produtor nessa mesma década. Os países centrais haviam parado, progressivamente, de produzir bauxita devido ao esgotamento, começando com a Grã-Bretanha e o Japão, na década de 40.

O comércio da bauxita cresceu dramaticamente, conforme um maior número de países, fora das regiões industrializadas da Europa e América do Norte, começavam a produzir o minério. 
Em primeiro lugar, conforme mostra a Tabela 2, as exportações mundiais de minério de bauxita chegaram ao ápice em 1990, entrando em declínio no início da década de 90, o que ilustra a tendência de crescimento em direção à transformação da bauxita em alumina dentro dos limites do país produtor, uma importante estratégia da industrialização para aumento de exportações (IAE), durante a terceira fase da globalização, que começou em meados da década de 70.

Tabela 2: Comércio mundial de bauxita (em toneladas)

\begin{tabular}{|c|c|c|c|c|c|}
\hline Ano & $\begin{array}{c}\text { Total mundial de } \\
\text { comercialização }\end{array}$ & $\begin{array}{c}\text { Parte da } \\
\text { produção }\end{array}$ & $\begin{array}{c}\text { Crescimento } \\
\text { percentual }\end{array}$ & $\begin{array}{c}\text { Parte dos } \\
\text { três maiores } \\
\text { exportadores }\end{array}$ & $\begin{array}{c}\text { Parte dos } \\
\text { dois maiores } \\
\text { importadores }\end{array}$ \\
\hline 1951 & 7.166 .000 & $66,5 \%$ & & $74,4 \%$ & $71,1 \%$ \\
\hline 1960 & 15.600 .000 & $57,8 \%$ & $118 \%$ & $63 \%$ & $72,2 \%$ \\
\hline 1970 & 27.100 .000 & $46,9 \%$ & $73,7 \%$ & $62,2 \%$ & $67,6 \%$ \\
\hline 1980 & 32.400 .000 & $36,3 \%$ & $19,6 \%$ & $67,5 \%$ & $61,6 \%$ \\
\hline 1990 & 35.753 .700 & $31,4 \%$ & $10,5 \%$ & $69,8 \%$ & $45,9 \%$ \\
\hline 1992 & 33.153 .700 & $30,6 \%$ & $-7,3 \%$ & $68,8 \%$ & $50,9 \%$ \\
\hline
\end{tabular}

OS TREAS MAIORES EXPORTADORES:
$1951 \quad$ Suriname, Guiana Inglesa, Indonésia
$1960 \quad$ Jamaica, Suriname, Guiana Inglesa
$1970 \quad$ Jamaica, Austrália, Suriname
$1980 \quad$ Guiné, Austrália, Jamaica
$1990 \quad$ Guiné, Austrália, Brasil
$1992 \quad$ Guiné, Austrália, Brasil

OS DOIS MAIORES IMPORTADORES:

$\begin{array}{ll}1951 & \text { U.S., Canadá } \\ 1960 & \text { U.S., Canadá } \\ 1970 & \text { U.S., Canadá } \\ 1980 & \text { U.S., Japão } \\ 1990 & \text { U.S., Rússia } \\ 1992 & \text { U.S., Rússia }\end{array}$

Fontes: USBM (vários anos); Minerals Yearbook; Metallgesellschaft (vários anos); Metallstatistik. UN (vários anos); World Trade Tables.

Tais esforços constituíram uma forma de nacionalização de recursos, destinada a captar uma parte maior dos benefícios trazidos pela extração de matérias-primas, por meio da criação de efeitos em cadeia (HIRSCHMAN, 1958, 1979; GIRVAN, 1976). O sucesso desses esforços 
estratégicos na mudança do volume da produção global de alumina é demonstrado na Tabela 3, a seguir.

Em segundo lugar, enquanto a fatia dos três maiores exportadores permaneceu relativamente estável, o número de membros desse seleto grupo modificou-se rapidamente ao longo do tempo. Em terceiro lugar, os EUA permaneceram os maiores importadores de bauxita do mundo, desde 1951.

Os dados existentes sobre o estágio de transformação da alumina, embora não cubram um período tão longo quanto o dos dados sobre a bauxita, apresentados acima, demonstram algumas mudanças semelhantes e algumas um tanto quanto diferentes na localização da produção de alumina no comércio mundial, em comparação com a produção e o comércio da bauxita.

Tabela 3: Volume total da produção mundial de alumina (em toneladas)

\begin{tabular}{|c|c|c|c|c|}
\hline Ano & $\begin{array}{c}\text { Total da } \\
\text { produção mundial }\end{array}$ & $\begin{array}{c}\text { Aumento } \\
\text { percentual }\end{array}$ & $\begin{array}{c}\text { Número de } \\
\text { países }\end{array}$ & $\begin{array}{c}\text { Parte dos três } \\
\text { maiores países }\end{array}$ \\
\hline 1960 & 4.566 .100 & - & 18 & $73 \%$ \\
\hline 1970 & 20.766 .000 & $355 \%$ & 24 & $50 \%$ \\
\hline 1980 & 33.381 .000 & $61 \%$ & 24 & $50 \%$ \\
\hline 1990 & 40.105 .000 & $20 \%$ & 25 & $48 \%$ \\
\hline 1995 & 42.200 .000 & $5 \%$ & 29 & $49 \%$ \\
\hline 1996 & 42.700 .000 & $1 \%$ & 29 & $50 \%$ \\
\hline
\end{tabular}

Fontes: USBM (vários anos); Minerals Yearbook; Metallgesellschaft (vários anos); Metallstatistik. UN (vários anos); World Trade Tables.

Há duas semelhanças básicas entre a alumina e a bauxita. Primeiro, assim como aconteceu com a bauxita, a taxa de crescimento da produção de alumina diminuiu significativamente nos últimos vinte anos e permanecerá possivelmente baixa no futuro. Segundo, o número de países produtores parece ter atingido um pico estável em 1970. Porém, ao contrário da bauxita, o papel dos países industrializados do centro com relação ao refinamento de alumina, em termos do número de países produtores, de fato, aumentou, com cinco países europeus entrando na produção durante os últimos trinta anos e apenas um, saindo. Fora da Europa, somente a Índia, o Suriname, a Turquia e a Venezuela entraram na produção durante o período. Porém, a fatia de produção fora da Europa, da América do Norte e do Japão aumentou de 15,8\% para 27,6\%, durante os últimos trinta anos.

O comércio mundial de alumina aumentou dramaticamente durante os últimos trinta anos, conforme mostra a Tabela 4. 
A fatia da produção mundial exportada, entretanto, dobrou nos últimos trinta anos, devido às políticas de nacionalização de recursos da IAE na Jamaica, Guiné, Suriname e Austrália. Essas ações, porém, não são necessariamente contrárias aos interesses das empresas de alumínio, pois a transformação da bauxita em alumina, processada em local próximo à mina, reduz grandemente os custos de transporte, uma vez que o volume de material foi reduzido à metade e ainda pode ser remetido como carga pelas firmas transportadoras, ao longo de milhares de milhas até as fundições de alumínio.

Tabela 4: Comércio mundial de alumina (em toneladas)

\begin{tabular}{|c|c|c|c|c|c|}
\hline Ano & $\begin{array}{c}\text { Total da } \\
\text { produção } \\
\text { mundial de } \\
\text { alumina }\end{array}$ & $\begin{array}{c}\text { Fatia da } \\
\text { produção } \\
\text { mundial }\end{array}$ & $\begin{array}{c}\text { Percentual } \\
\text { de } \\
\text { aumento }\end{array}$ & $\begin{array}{c}\text { Fatia dos três } \\
\text { maiores } \\
\text { exportadores }\end{array}$ & $\begin{array}{c}\text { Fatia dos dois } \\
\text { maiores } \\
\text { importadores }\end{array}$ \\
\hline 1960 & 703.600 & $15,4 \%$ & & $67,1 \%$ & $64 \%$ \\
\hline 1970 & 5.642 .828 & $27,2 \%$ & $702 \%$ & $63 \%$ & $62 \%$ \\
\hline 1980 & 10.558 .140 & $31,6 \%$ & $87 \%$ & $76 \%$ & $55 \%$ \\
\hline 1990 & 10.339 .300 & $48,0 \%$ & $-2,8 \%$ & $62,4 \%$ & $33 \%$ \\
\hline 1992 & 10.222 .300 & $48,8 \%$ & $-1,0 \%$ & $66,8 \%$ & $39 \%$ \\
\hline
\end{tabular}

OS TRÊS MAIORES EXPORTADORES:

$\begin{array}{ll}1962 & \text { Jamaica, Guiné, Canadá } \\ 1970 & \text { Austrália, Jamaica, Suriname } \\ 1980 & \text { Austrália, Jamaica, Suriname } \\ 1990 & \text { Austrália, Jamaica, Suriname } \\ 1992 & \text { Austrália, Jamaica, Suriname }\end{array}$

OS DOIS MAIORES IMPORTADORES:

$\begin{array}{ll}1962 & \text { Noruega, EUA } \\ 1970 & \text { EUA, Noruega } \\ 1980 & \text { EUA, Noruega } \\ 1990 & \text { EUA, Canadá } \\ 1992 & \text { EUA, Canadá }\end{array}$

Fontes: USBM (vários anos); Minerals Yearbook; Metallgesellschaft (vários anos); Metallstatistik. UN (vários anos); World Trade Tables.

A fatia dos três maiores exportadores permaneceu relativamente estável, assim como permaneceram os mesmos os três maiores exportadores, desde 1970. A fatia dos dois maiores importadores diminuiu significativamente, pois um crescente número de países entrou para a indústria do alumínio, em conseqüência das políticas de desenvolvimento da IAE, durante a terceira fase da globalização. 
As ações estratégicas das empresas globais de alumínio, no sentido de aumentar as vendas e os lucros, tiveram grande implicação em vários países periféricos e semiperiféricos, que buscavam promover o desenvolvimento econômico. Nas décadas de 40, 50 e 60, durante a segunda fase da globalização, as empresas multinacionais de alumínio começaram a procurar mercados fora dos países industrializados do centro. Como a maioria dos países periféricos e semiperiféricos não tinha grande potencial hidrelétrico e de bauxita, o acesso a esses mercados, normalmente, tomou a forma de usinas de processamento final de alumínio, que produziam bens de consumo para o mercado interno, e, às vezes, de usinas de semiprocessamento, que produziam folhas, cabos ou outros produtos para as fábricas locais. Entretanto, poucos países possuíam as matérias-primas necessárias e um grande mercado interno que justificasse uma Industrialização para Substituição de Importação totalmente integrada, levada a cabo pelos grandes do alumínio e pelo capital interno.

Tabela 5: Total da produção mundial de alumínio (em toneladas)

\begin{tabular}{|c|c|r|r|c|}
\hline Ano & $\begin{array}{c}\text { Total da produção } \\
\text { mundial de alumínio }\end{array}$ & $\begin{array}{c}\text { Percentual } \\
\text { de aumento }\end{array}$ & $\begin{array}{c}\text { Número de } \\
\text { países }\end{array}$ & $\begin{array}{c}\text { Fatia dos três } \\
\text { maiores países }\end{array}$ \\
\hline 1900 & 6.139 & & 4 & $90,1 \%$ \\
\hline 1940 & 830.000 & $13.420 \%$ & 14 & $63,4 \%$ \\
\hline 1950 & 1.500 .000 & $80,7 \%$ & 18 & $80,1 \%$ \\
\hline 1960 & 4.490 .000 & $199 \%$ & 24 & $70,3 \%$ \\
\hline 1970 & 9.654 .000 & $115 \%$ & 33 & $58,8 \%$ \\
\hline 1980 & 15.382 .000 & $59,3 \%$ & 42 & $48,8 \%$ \\
\hline 1990 & 17.817 .000 & $15,8 \%$ & 41 & $43,9 \%$ \\
\hline 1995 & 19.400 .000 & $9 \%$ & 44 & $42,8 \%$ \\
\hline
\end{tabular}

OS TRÊS MAIORES PRODUTORES:

$\begin{array}{ll}1900 & \text { EUA, Suíça, França } \\ 1940 & \text { Alemanha, EUA, Canadá } \\ 1950 & \text { EUA, Canadá, URSS } \\ 1960 & \text { EUA, Canadá, URSS } \\ 1970 & \text { EUA, URSS, Canadá } \\ 1980 & \text { EUA, URSS, Japão } \\ 1990 & \text { EUA, URSS, Canadá } \\ 1995 & \text { EUA, Rússia, Canadá }\end{array}$

Fontes: USBM (vários anos); Minerals Yearbook; Metallgesellschaft (vários anos); Metallstatistik. UN (vários anos); World Trade Tables.

Como resultado disso, o estágio de fundição de alumínio também passou por significativas mudanças em termos de localização e comér- 
cio. Conforme mostra a Tabela 5, o percentual de aumento da produção mundial de alumínio caiu na última década, porém o número de países produtores de alumínio cresceu de forma estável, desde 1900 (as razões para esse crescimento notável no número de países produtores será discutida com detalhe na Seção 4). O grau de concentração nacional da produção, entretanto, diminuiu significativa e consistentemente desde 1900. Os nomes dos três maiores produtores permaneceram quase constantes desde 1950.

Conforme mostra a Tabela 6, o papel do comércio mundial na indústria do alumínio aumentou consistentemente desde 1960, enquanto a concentração nacional de exportadores caiu rapidamente entre 1960 e 1980, porém permaneceu quase a mesma durante as décadas de 80 e 90. A fatia dos dois maiores importadores é virtualmente idêntica em 1962 e 1988. A Alemanha e o Reino Unido eram, há muito, importadores em grande escala, enquanto o Japão e os EUA também começaram a tornar-se importantes importadores nas duas últimas décadas.

Tabela 6: O comércio mundial de alumínio (em toneladas)

\begin{tabular}{|c|c|c|c|c|c|}
\hline Ano & $\begin{array}{c}\text { Total do comércio } \\
\text { mundial de } \\
\text { alumínio }\end{array}$ & $\begin{array}{c}\text { Fatia da } \\
\text { produção } \\
\text { mundial }\end{array}$ & $\begin{array}{c}\text { Percentual } \\
\text { de aumento }\end{array}$ & $\begin{array}{c}\text { Fatia dos } \\
\text { três maiores } \\
\text { exportadores }\end{array}$ & $\begin{array}{c}\text { Fatia dos } \\
\text { dois maiores } \\
\text { importadores }\end{array}$ \\
\hline 1960 & 1.143 .300 & $25,5 \%$ & $141 \%$ & $78,6 \%$ & $44,7 \%$ \\
1970 & 2.754 .563 & $28,5 \%$ & $107 \%$ & $34,5 \%$ & $34,4 \%$ \\
1980 & 5.705 .352 & $37,1 \%$ & $107 \%$ & $31 \%$ \\
1990 & 8.717 .300 & $45,1 \%$ & $52,8 \%$ & $34,2 \%$ & $40,5 \%$ \\
1992 & 9.579 .700 & $49,2 \%$ & $10,3 \%$ & $33,4 \%$ & $38,7 \%$ \\
\hline
\end{tabular}

OS TRÊS MAIORES EXPORTADORES:

1960 Canadá, EUA, Noruega

1970 Noruega, EUA, Canadá

1980 Canadá, EUA, Noruega

1990 Canadá, Austrália, EUA

1992 Canadá, Austrália, Rússia

OS DOIS MAIORES IMPORTADORES:

1960 Reino Unido, Alemanha Ocidental

1970 Alemanha Ocidental, Reino Unido

1980 Japão, Alemanha Ocidental

1990 Japão, EUA

1992 Japão, EUA

Fontes: USBM (vários anos); Minerals Yearbook; Metallgesellschaft (vários anos); Metallstatistik. UN (vários anos); World Trade Tables. 
Em suma, em 1960, 55\% do alumínio embutido foram comercializados internacionalmente como bauxita, 11\%, como alumina e 34\%, como alumínio primário. Por volta de 1992, 36\% do alumínio embutido foram internacionalmente comercializados como bauxita, 22\%, como alumina e 42\%, como alumínio primário. Esse revés constituiu, essencialmente, uma fuga das vantagens naturais de transporte para a bauxita e a alumina em direção às tentativas, feitas pelos países produtores de bauxita, de captar valor agregado no processamento, por meio das estratégias da IAE em alumina, e, em alguns casos, na produção de alumínio.

Como podemos explicar esse processo mutável da globalização da indústria de alumínio? A próxima seção analisa a ligação da natureza mutável da globalização, as estratégias de competição das empresas e as estratégias de desenvolvimento estatal que causaram essas mudanças.

\section{GLOBALIZAÇÃO, EMPRESAS E ESTADOS}

\section{Ascensão e queda do oligopólio do alumínio}

A criação da estrutura de oligopólio na indústria do alumínio, nos primeiros anos, resultou do controle das patentes de fundição de alumínio Hall-Heroult, da Alcoa, na América do Norte, e da Alusuisse e Pechiney, na Europa, que entraram na indústria em 1888. Esse controle do processo tecnológico proporcionou a essas empresas a vantagem dos pioneiros, fornecendo-lhes a oportunidade de controlar os melhores depósitos de bauxita e sítios hidrelétricos em suas respectivas regiões operacionais (BARHAM, 1994). Essas empresas utilizaram a proteção de patente para forçar outra empresa competidora a sair da indústria e evitar a entrada de outras, até pouco antes da I Guerra Mundial (cf. WALLACE, 1937; MARLIO, 1947; CARR, 1952; SMITH, 1988; BARHAM, 1994). Essas empresas, que permaneceram continuamente em operação desde 1888, foram as pioneiras entre as grandes empresas norteamericanas e européias privadas e verticalmente integradas, que foram chamadas "as grandes do alumínio", as "Seis Irmãs" ou, mais simplesmente, os membros do oligopólio do alumínio.

Diversas empresas entraram na indústria do alumínio em outras partes do mundo, nas primeiras décadas da história dessa indústria. As recém-chegadas eram a British Aluminum Company (BAC), em 1896, a VAW, na Alemanha, em 1918, a Montecatini-Edison, na Itália, em 1928, a Showa Denko, no Japão, em 1934, e a Nippon Light Metal, também no Japão, em 1940. 
Apesar da proteção institucional que gozavam, devido à vigência da patente e ao apoio do governo, essas três empresas eram, inicialmente, bastante pequenas e enfrentaram dois grandes desafios: como vender um produto que era completamente desconhecido dos clientes em potencial e como obter acesso aos insumos necessários à produção. A fim de vencer o primeiro obstáculo, as grandes do alumínio tiveram de criar um nicho para si, nas economias nacionais dentro das quais operavam e também na economia mundial. Esse nicho, onde seria colocado no mercado o novo produto, o alumínio, foi criado pelas próprias grandes, por meio de extensa pesquisa e desenvolvimento, tanto na adequação do alumínio como substituto para outros metais, especialmente cobre e aço, nos produtos existentes, como nos novos produtos, feitos de alumínio. Eram cruciais nesse processo as ações para a contínua redução de custo da produção de alumínio, a fim de torná-lo competitivo entre os metais existentes. Em muitos casos, porém, as grandes foram inicialmente incapazes de convencer outras empresas a utilizar o alumínio na manufatura de produtos existentes ou novos; em tais situações, elas integravam-se mais intensamente na produção de insumos industriais e mesmo em bens de consumo final, como potes e panelas (SMITH, 1988).

Essa ênfase na pesquisa e desenvolvimento e na integração permaneceram, desde então, aspectos fundamentais das estratégias das grandes do alumínio. A empresa líder no desenvolvimento tecnológico, desde a origem da indústria, é a Alcoa. Sua lista de inovações em processos e produtos é de proporções espantosas, indo da introdução de utensílios de cozinha, feitos de alumínio, partes da estrutura das bicicletas, barramentos elétricos, cabeamento telefônico e cabeamento elétrico de longa distância, entre 1889 e 1899, até a dramática redução do peso das latas de refrigerantes de alumínio e o desenvolvimento de peças aeroespaciais forjadas em metal calcinado, na década de 80 (para obter a lista completa dos resultados da longa história de pesquisa e desenvolvimento da Alcoa, ver Graham e Pruitt (1990, p. 511-527)). Esses esforços resultaram em um enorme crescimento do consumo de alumínio ao longo dos cem anos de história da indústria.

Com o propósito de vencer o segundo obstáculo para seu crescimento - a necessidade de ter acesso a insumos essenciais à produção , as grandes do alumínio adotaram a estratégia da integração para trás, na extração e no processamento de matérias-primas. Os dois insumos básicos são a bauxita - o minério de alumínio que ocorre naturalmente - e a eletricidade - normalmente hidrelétrica, devido à grande e constante demanda de energia da produção de alumínio. As grandes do 
alumínio tiveram acesso a esses recursos, inicialmente, por meio da aquisição de empresas existentes, produtoras desses insumos, e da aquisição de locais não desenvolvidos, com depósitos de bauxita ou grande potencial hidrelétrico, nos países onde as grandes estavam baseadas, bem como em países vizinhos (WALLACE, 1937; BRUBAKER, 1967; SMITH, 1988).

A chegada da Alcoa a um país vizinho, o Canadá, a fim de adquirir sítios hidrelétricos, levou, de fato, à criação de uma subsidiária da Alcoa, da qual a empresa teve de desfazer-se em razão das leis norteamericanas antitruste. Essa empresa subsidiária, a Alcan, tornou-se a quarta grande do alumínio, após sua venda formal, em 1928, seguida da completa separação dos acionistas (SMITH, 1988). As medidas antitruste do governo norte-americano também tiveram um grande papel na fundação e no subseqüente crescimento, em 1941 e 1946, respectivamente, dos dois últimos membros do oligopólio formado pelas grandes do alumínio: a Reynolds Metals e a Kaiser Aluminum, ambas sediadas nos Estados Unidos. As instalações com fins bélicos, construídas pelo governo americano, foram vendidas com grandes descontos, após a guerra, para essas empresas. O governo americano também apoiou as ações dessas empresas a fim de obter acesso à bauxita jamaicana.

A separação entre a Alcoa e a Alcan, sua subsidiária canadense, no início da década de 50, de acordo com os termos finais do processo antitruste nos Estados Unidos, produziu o terceiro novo membro norteamericano da indústria do alumínio.

Os desafiantes em potencial do oligopólio existente entre as grandes rapidamente tomaram seus lugares nesse mesmo oligopólio. Após o apoio concedido pelo governo americano, permitindo que a Reynolds e a Kaiser atingissem a integração vertical e chegassem a um tamanho razoável, essas duas empresas e a Alcan adotaram a estratégia das grandes da época, conduzindo pesquisas e esforços de desenvolvimento em larga escala, integrando horizontalmente para frente, enquanto seguiam a liderança de preços e os modelos informais de regulamentação da produção adotados pelo oligopólio (PECK, 1961; GRAHAM, 1982; SMITH, 1988; DAVIS, 1989).

Um terceiro importante obstáculo ao crescimento das três grandes do alumínio surgiu entre 1910 e 1940. Conforme os diversos usos do alumínio, especialmente para fins militares, iam se tornando cada vez mais conhecidos, os governos de outros países da Europa ocidental quiseram implantar indústrias de alumínio nacionais, dentro de suas fronteiras, para produzir material bélico, durante os períodos que levaram à I e II Guerras Mundiais. A fim de vencer esse novo obstáculo, as 
grandes do alumínio na Europa - Pechiney e Alusuisse - cooperaram com os governos de diversos países europeus, por meio da venda de tecnologia, de técnicas de administração e, em alguns casos, de matérias-primas às empresas da emergente segunda forma organizacional da indústria do alumínio - as empresas estatais situadas nos países de economia de mercado da Europa (WALLACE, 1937; MARLIO, 1947).

Após a II Guerra Mundial, três grandes fatores combinaram-se para produzir um enorme crescimento na produção mundial da indústria de alumínio e no número de empresas envolvidas nessa indústria. Em primeiro lugar, o rápido crescimento econômico mundial levou a uma expansão dos mercados de alumínio, incluindo transporte, equipamento elétrico, construção e embalagens. As maiores empresas de alumínio tiveram um importante papel nesse processo, por meio de suas pesquisas e do desenvolvimento de novos produtos de alumínio em substituição a outros materiais, como cobre, aço, chumbo e madei$\mathrm{ra}$, nos usos existentes e como insumos essenciais para novos produtos. Esse rápido crescimento do consumo de alumínio proporcionou uma excelente oportunidade para a entrada de novas empresas na indústria de alumínio, um processo que será examinado em detalhe a seguir. Finalmente, a independência de antigas áreas coloniais, começando com a Índia, no final da década de 40, e as grandes expansões econômicas em áreas da periferia, especialmente a América Latina, tornaram disponíveis depósitos de bauxita, áreas com potencial hidrelétrico e novos mercados tanto para as grandes como para os recém-chegados à indústria. Durante o período pós-guerra, porém, a disponibilidade desses recursos e mercados foi grandemente condicionada pelos esforços de promover o desenvolvimento econômico, primeiramente por meio da industrialização para substituição de importações e, posteriormente, pelas estratégias de industrialização para exportação, bem como pelos movimentos de nacionalização de recursos, em muitos países periféricos.

A Tabela 7 ilustra a ascensão e o subseqüente declínio do oligopólio do alumínio, no estágio da mineração da bauxita, ao passo que a Tabela 8 ilustra esse processo no estágio do refinamento do alumínio e a Tabela 9, no estágio da fundição do alumínio. 
Tabela 7: Fatia da capacidade mundial de produção de bauxita alocada às "grandes do alumínio".

\begin{tabular}{|l|r|r|r|r|r|r|r|}
\hline & 1955 & 1963 & 1969 & 1971 & 1975 & 1979 & 1997 \\
\hline Alcoa & 28,2 & 20,0 & 16,7 & 16,2 & 19,6 & 17,2 & 15,7 \\
\hline Alcan & 25,6 & 22,4 & 14,3 & 6,6 & 5,6 & 6,6 & 6,0 \\
\hline Reynolds & 16,4 & 13,7 & 7,0 & 10,4 & 8,0 & 5,0 & 4,2 \\
\hline Kaiser & 11,0 & 17,3 & 19,7 & 15,6 & 11,4 & 8,2 & 4,2 \\
\hline Pechiney & 4,7 & 6,7 & 5,2 & 4,9 & 4,6 & 2,8 & 1,4 \\
\hline Alusuisse & 2,3 & 1,9 & 1,8 & 3,3 & 3,8 & 5,2 & 5,9 \\
\hline Total & 88,2 & 82,0 & 64,77 & 57,0 & 53,0 & 45,0 & 37,42 \\
\hline
\end{tabular}

Observação: As minas na antiga União Soviética, Europa Oriental e China foram excluídas de todos os anos para permitir uma comparação ao longo do tempo, embora a reintegração dessas regiões, na última década, tenha transformado essas áreas em fornecedores em potencial e, em alguns casos, fornecedores e/ou mercados de fato para a indústria mundial.

Fontes: 1955 e 1963: Stuckey (1983, p. 84).

1969: CRA Economic Analysis of the Aluminum Industry (1971, p. 3-47).

1971: Jamaican Bauxite Institute.

1975: Metal Bulletin (1977).

1979: UNCTAD (1984, p. 45).

1997: com base nas estimativas da USBM (1995).

Nacionalização das reservas da Alcan na Guiana, em 1971.

Tabela 8: Fatia da capacidade mundial de produção de alumina alocada às "grandes do alumínio".

\begin{tabular}{|l|r|r|r|r|r|r|r|r|}
\hline & 1955 & 1963 & 1969 & 1971 & 1975 & 1979 & 1988 & 1991 \\
\hline Alcoa & 24,8 & 18,0 & 24,1 & 23,0 & 19,8 & 27,6 & 18,7 & 19,6 \\
Alcan & 27,3 & 26,3 & 20,5 & 19,0 & 12,6 & 13,9 & 13,4 & 10,8 \\
Reynolds & 16,9 & 15,4 & 12,8 & 11,1 & 10,8 & 9,2 & 9,7 & 7,1 \\
Kaiser & 12,3 & 11,7 & 14,9 & 12,2 & 9,7 & 9,4 & 6,8 & 6,8 \\
Pechiney & 5,1 & 8,6 & 9,2 & 11,0 & 8,3 & 8,9 & 6,6 & 4,8 \\
Alusuisse & 4,2 & 4,6 & 2,7 & 2,9 & 3,2 & 4,8 & 4,2 & 3,7 \\
Total & 90,6 & 84,6 & 84,2 & 79,2 & 64,4 & 73,8 & 59,4 & 52,8 \\
\hline
\end{tabular}

Fontes: 1955, 1963, 1971 e 1979: Stuckey (1979, p. 84).

1969: CRA Economic Analysis of the Aluminum Industry (1971, p. 3-48).

1975: Metal Bulletin World Aluminum Survey (1977, p. 101-107).

1988 e 1991: Economic Analysis of the Aluminum Industry.

Observação: Usinas da antiga União Soviética, Europa Oriental e China foram excluídas de todos os anos para permitir uma comparação ao longo do tempo, embora a reintegração dessas regiões, na última década, tenha transformado essas áreas em fornecedores em potencial e, em alguns casos, fornecedores e/ou mercados de fato para a indústria mundial. 
Tabela 9: Fatia da capacidade mundial de produção de alumínio alocada às "grandes do alumínio".

\begin{tabular}{|l|r|r|r|r|r|r|r|r|r|r|}
\hline & 1954 & 1959 & 1964 & 1969 & 1974 & 1979 & 1984 & 1989 & 1991 & 1996 (est.) \\
\hline Alcoa & 21,8 & 20,0 & 17,1 & 17,7 & 14,5 & 14,5 & 13,3 & 12,4 & 12,5 & 11,5 \\
\hline Alcan & 23,9 & 21,7 & 18,6 & 14,2 & 14,2 & 11,5 & 12,9 & 12,0 & 12,3 & 10,8 \\
\hline Reynolds & 14,7 & 16,2 & 12,6 & 14,0 & 10,6 & 9,9 & 8,8 & 6,9 & 7,0 & 6,2 \\
\hline Kaiser & 16,0 & 13,3 & 13,7 & 11,0 & 8,0 & 8,2 & 8,1 & 5,4 & 4,3 & 3,3 \\
\hline Pechiney & 4,7 & 4,2 & 5,3 & 5,3 & 5,3 & 6,3 & 5,8 & 6,7 & 5,4 & 6,3 \\
\hline Alusuisse & 3,9 & 2,5 & 3,1 & 2,5 & 3,3 & 3,4 & 3,0 & 3,1 & 3,0 & 2,7 \\
\hline Total & 85,0 & 77,9 & 70,4 & 64,7 & 55,9 & 53,8 & 51,9 & 46,5 & 44,5 & 40,8 \\
\hline
\end{tabular}

Fontes: 1954-1989: calculado a partir dos dados do Minerals Yearbook da USBM. 1991: Economic Analysis of the Aluminum Industry (1991, p. 70).

1996: estimativas baseadas em Primary Aluminum Plants Worldwide (1990), USBM e publicações da indústria.

Observação: Usinas da antiga União Soviética, Europa Oriental e China foram excluídas de todos os anos para permitir uma comparação ao longo do tempo, embora a reintegração dessas regiões, na última década, tenha transformado essas áreas em fornecedores em potencial e, em alguns casos, fornecedores e/ou mercados de fato para a indústria mundial.

Como explicar o rápido e contínuo declínio do controle do oligopólio do alumínio? Na década de 50, esse estável oligopólio enfrentou quatro grandes obstáculos ao seu contínuo sucesso financeiro, no contexto de uma crescente demanda mundial de alumínio. Em primeiro lugar, o cartel internacional - mecanismo-chave para a coordenação das ações de empresas competidoras com o propósito de controlar os preços e a produção -, ao mesmo tempo que desencorajava a entrada de novas empresas e mantinha os níveis de preços baixos o suficiente para encorajar a substituição de outros materiais pelo alumínio, entre 1888 e 1940, foi efetivamente destruído pelos esforços do governo americano para aumentar a competição na indústria. Antes da década de 50, as grandes eram capazes de acomodar a entrada de novas formas organizacionais e novas empresas, criando interdependências entre os recém-chegados e as grandes, pois estas últimas serviam como fornecedoras de matérias-primas e tecnologia, bem como serviam de parceiras dos recém-chegados, nos cartéis internacionais. As medidas antitruste dos Estados Unidos deixaram essa forma de coordenação fora do alcance das grandes, forçando-as a encontrar novos meios de coordenar preços e níveis de produção. 
Em segundo lugar, a indústria estava tornando-se cada vez mais global, exigindo que as grandes operassem em mais países, bastante dispersos em todo o mundo, e dificultando o planejamento e o controle administrativo. A produção de matérias-primas, produtos intermediários e bens finais, bem como a venda desses produtos finais pelas grandes estavam sendo feitas em um número cada vez maior de países na Europa, América Latina e Ásia (BRUBAKER, 1967).

Em terceiro lugar, o rápido crescimento do consumo mundial de alumínio, resultado, em grande parte, das ações de pesquisa e desenvolvimento iniciadas pelas grandes, exigia investimentos cada vez maiores nas instalações de produção. A escala em expansão das instalações de produção é evidente: o tamanho médio para todas as fundições, em 1954, era de 40.000 toneladas por ano, enquanto, em 1989, o tamanho médio era de quase 130.000 toneladas por ano. O aumento do custo de capital das fundições de alumínio foi ainda mais rápido: as maiores e mais modernas usinas, construídas na década de 50, tinham capacidade para 100.000 toneladas por ano e um custo de US\$100 milhões, ao passo que as maiores usinas, construídas nos últimos anos, produzem cerca de 400.000 toneladas de alumínio por ano, com um custo de investimento de capital em torno de US\$ 1,5 bilhão. O tamanho e o custo dessas instalações fizeram com que as maiores empresas relutassem em investir nas instalações de produção fora de suas bases, nos países desenvolvidos, sem dividir o risco com outras empresas.

Finalmente, em quarto lugar, apesar da natureza global da indústria, as fronteiras nacionais continuaram importantes em alguns casos, especialmente no Terceiro Mundo. As ações dos governos do Terceiro Mundo, especialmente as destinadas a promover a produção interna dos maiores produtos industriais, como o alumínio, afetaram a estrutura e a operação da indústria mundial, em decorrência do controle governamental do acesso aos mercados internos e dos seus recursos naturais. Essas fronteiras nacionais tiveram um importante papel, especialmente no Terceiro Mundo, em países com grandes territórios e ricos em recursos, como o Brasil, a Índia e a Indonésia, com governos que exigiam a participação privada ou estatal, como parceiros com participação acionária nas novas instalações de produção, dentro de seus territórios.

As fronteiras nacionais também são importantes nos países em desenvolvimento, em alguns casos. Apesar do grande papel desempenhado pelo comércio internacional na indústria mundial de alumínio, a economia nacional permanece como uma importante comunidade a ser examinada, devido a, pelo menos, duas razões. Em primeiro lugar, o ambiente institucional, proporcionado pelo país onde a em- 
presa está baseada, tem efeitos importantes na capacidade de sobrevivência dessas empresas. Um dos efeitos mais importantes na história da indústria mundial de alumínio tem sido os esforços dos governos para auxiliar suas empresas nacionais a ter acesso a recursos essenciais. Dois exemplos ilustram esse papel do ambiente institucional: primeiro, durante o final da década de 40 e início da década de 50, o governo americano recorreu a pressões diplomáticas e econômicas sobre o governo britânico para que as empresas norte-americanas de alumínio tivessem acesso aos depósitos de bauxita na Jamaica (O'HEARN, 1994); segundo, durante a década de 70, o governo japonês usou meios que incluíam auxílio ao desenvolvimento e empréstimos de bancos estatais como iniciativas para a construção de joint ventures para a fundição de alumínio entre um consórcio japonês e empresas estatais no Brasil e na Venezuela.

Em segundo lugar, o volume e o conseqüente custo de transporte para lingotes de alumínio e a inovação tecnológica no transporte de alumínio fundido incentivaram a localização dos estágios de fundição e fabricação de alumínio no país consumidor do próprio alumínio. Essa localização da produção significou que mercados nacionais relativamente distintos haviam persistido.

A partir da década de 50, a fim de resolver esses problemas e manter o sucesso financeiro, as seis grandes começaram a fazer uso cada vez mais amplo de um novo mecanismo de coordenação, a joint venture.

\section{A entrada de novos tipos de empresa}

Os mesmos fatores que, após a II Guerra Mundial levaram ao crescimento das maiores empresas de alumínio e a sua expansão geográfica, levaram também à entrada de um grande número de pequenas empresas (companhias menores, baseadas nos países centrais) na indústria mundial de alumínio. O crescimento do número dessas empresas na indústria global do alumínio, em um ambiente competitivo, dominado pelas grandes empresas, foi extremamente rápido, como também foi rápido o crescimento do número de empresas estatais e japonesas nessa indústria, conforme mostra a Tabela 10. 
Tabela 10: Número de pequenas empresas estatais e japonesas na indústria global do alumínio

\begin{tabular}{|c|c|c|c|c|}
\hline & Pequenas empresas & \multicolumn{2}{|c|}{ Empresas estatais } & Empresas japonesas \\
\hline & & Periferia & Centro & \\
\hline 1888 & 1 & 0 & 0 & 0 \\
\hline 1900 & 0 & 0 & 0 & 0 \\
\hline 1910 & 1 & 0 & 0 & 0 \\
\hline 1920 & 1 & 0 & 2 & 0 \\
\hline 1930 & 2 & 0 & 3 & 0 \\
\hline 1940 & 5 & 1 & 3 & 5 \\
\hline 1950 & 5 & 1 & 4 & 3 \\
\hline 1960 & 9 & 2 & 6 & 5 \\
\hline 1970 & 19 & 3 & 7 & 6 \\
\hline 1980 & 18 & 13 & 8 & 7 \\
\hline 1990 & 25 & 15 & 9 & 9 \\
\hline 1991 & 25 & 15 & & \\
\hline
\end{tabular}

Fontes: USBM, ABMS e publicações da indústria.

Enquanto os recém-chegados competiam com as grandes nos mercados dos países industrializados, as pequenas empresas também cooperavam com as grandes em joint ventures, em um esforço para ter acesso a depósitos de bauxita e locais com potencial hidrelétrico e para explorá-los fora daqueles países. De forma similar, muitas das empresas estatais formaram joint ventures com as grandes e também com as pequenas empresas, e igualmente com empresas japonesas. A próxima seção examina como esse mecanismo de cooperação, a joint venture, hoje em dia amplamente reconhecida como uma marca registrada da globalização, transformou a indústria global do alumínio.

\section{O papel das joint ventures}

Durante as décadas de 80 e 90, a utilização de joint ventures tornou-se uma estratégia crítica para muitas empresas, especialmente aquelas que operavam em muitos países. As joint ventures são, na realidade, uma marca registrada dessa última fase da globalização. Entretanto, elas não são uma nova invenção. A indústria do alumínio foi pioneira nessa estratégia de compartilhar riscos, custos, tecnologia e conhecimento em uma indústria globalizada. As primeiras joint ventures na indústria do alumínio foram formadas em 1943, entre a Alcan e empresas locais na Suécia e na Índia (STUCKEY, 1983, p. 345). O ritmo cada vez maior da globalização na busca de matérias-primas e mercados em áreas cada vez mais remotas e politicamente voláteis do mundo 
levou, na década de 50, os seis membros do oligopólio do alumínio (as maiores empresas globais de alumínio ou "as grandes") a iniciar a ampla utilização da modalidade de joint ventures, como um mecanismo de cooperação entre si e com outros tipos de organização existentes na indústria (STUCKEY, 1983). As joint ventures - uma modalidade comum em várias indústrias na quarta fase da globalização (HARRISON, 1994) - não eram muito comuns há 50 anos; grandes empresas, especialmente as de matéria-prima, normalmente investiam em minas e instalações de processamento próprias. Entretanto, essas joint ventures para cooperação deram mais força a cada uma das grandes na competição direta com suas principais rivais durante esse período: as outras grandes. A força adicional foi resultado da diminuição de custos, provocada pelo compartilhamento entre os parceiros das joint ventures dos investimentos em escala cada vez maior e mais rápida nas minas de bauxita, refinarias de alumina e fundições de alumínio. Essa estratégia permitiu às grandes uma expansão para suprir a crescente demanda criada pelo desenvolvimento econômico geral, pelas vantagens tecnológicas do alumínio para uso em muitas indústrias e por suas vantagens econômicas (CICCANTELL, 1994). Atualmente, uma característica amplamente reconhecida da globalização é o desenvolvimento de joint ventures, contratos a longo prazo e outros mecanismos de cooperação interempresarial; as grandes da indústria do alumínio foram as pioneiras no uso desse mecanismo em todo o mundo, como parte de seus esforços para manter sua posição dominante na indústria global do alumínio. A recorrência à estratégia de joint venture cresceu consistentemente em todos os três estágios da indústria do alumínio, desde a década de 50, conforme mostra a Tabela 11.

Como explicar a rápida disseminação dessa inovação organizacional? A história começa com o papel desempenhado pelas grandes empresas do alumínio. No final da década de 60 e início da década de 70, o esgotamento das matérias-primas e o aumento dos custos da energia elétrica nos países do centro, além do rápido crescimento da demanda de alumínio em todo o mundo, levaram as empresas globais de alumínio e alguns países do centro, mais especificamente o Japão, a procurar expandir suas operações em diversos países periféricos e semiperiféricos, a fim de exportar alumínio aos seus mercados internos (CICCANTELL, 1994). Tais mudanças criaram oportunidades para que vários desses países fora do centro promovessem a Industrialização para Aumento de Exportação (IAE) na indústria do alumínio, mais comumente por meio de joint ventures e contratos a longo prazo, envolvendo consórcios de empresas do Japão, apoiadas pelo governo japonês, e em- 
presas estatais em países semiperiféricos, incluindo o Brasil, a Venezuela e a Indonésia. Essas joint ventures trouxeram novos e maiores competidores para a indústria global do alumínio, na forma de empresas estatais, responsáveis tanto pela obtenção de lucros, como pela promoção do desenvolvimento econômico e social. A partir de meados da década de 70, as grandes empresas do alumínio também passaram a recorrer cada vez mais às joint ventures em países com baixos custos de energia para suprir seus mercados internos na América do Norte e Europa.

Tabela 11: Número de joint ventures na indústria de alumínio

\begin{tabular}{|c|c|c|c|c|}
\hline & Bauxita & Alumina & Alumínio & $\begin{array}{c}\text { Fatia da capacidade } \\
\text { mundial em alumínio }\end{array}$ \\
\hline 1943 & & & 2 & \\
\hline 1954 & & & 9 & $7 \%$ \\
\hline 1959 & & & 18 & $20 \%$ \\
\hline 1964 & & & 24 & $23 \%$ \\
\hline 1969 & 10 & 8 & 32 & $32 \%$ \\
\hline 1974 & & & & 35 \\
\hline 1975 & $18(59 \%)$ & $17(42 \%)$ & 38 & $38 \%$ \\
\hline 1979 & 20 & 22 & 40 & $43 \%$ \\
\hline 1984 & & & 43 & $49 \%$ \\
\hline 1989 & & & & \\
\hline 1996 & & & & \\
\hline 1997 & $22(79,3 \%)$ & & & \\
\hline
\end{tabular}

Fontes: Cálculos feitos a partir do Minerals Yearbook e de outras publicações da indústria. Dados relativos a 1969, para bauxita e alumínio, coletados em CRA, Economic Analysis of the Aluminum Industry (1971, Tabela 3-2). Dados relativos a 1979, para bauxita e alumínio, coletados em Stuckey (1983, p. 322-327). Dados relativos a 1975, para bauxita, alumina e alumínio, coletados em Metal Bulletin.

Entretanto, essas joint ventures para fins de cooperação, combinadas com certas mudanças imprevistas na economia mundial e na economia dos Estados Unidos, nas décadas de 70 e 80, desestabilizaram a indústria global do alumínio e o controle exercido sobre ela pelas grandes. Os dramáticos aumentos no preço da eletricidade, resultantes das duas crises do petróleo, tornaram pouco competitiva grande parte da capacidade de fundição das grandes em seus países de origem, forçando-as a reestruturar-se e até mesmo a desfazer-se de grandes instalações de produção. Ao mesmo tempo, o rápido crescimento da economia do Japão levou ao surgimento de empresas de alumínio japonesas, que se tornaram formidáveis competidoras das grandes. A disseminação 
geográfica da indústria em diversos países periféricos e semiperiféricos introduziu também importantes competidores novos: as empresas estatais. Empresas pequenas, baseadas no centro, apoiadas pelas joint ventures, também se tornaram notáveis competidoras das grandes. Finalmente, os avanços tecnológicos no uso de materiais que podiam ser substitutos do alumínio em muitos usos levaram a uma abrupta diminuição do ritmo de crescimento da demanda desse metal.

\section{CONSIDERAÇÕES FINAIS}

No contexto dessas mudanças que caracterizaram a quarta fase da globalização, desde meados da década de 80 , as joint ventures, criadas inicialmente pelas grandes para fortalecer sua posição na competição com as demais, tiveram importantes efeitos organizacionais, que as grandes não haviam antecipado. As joint ventures deram forças adicionais às novas empresas competidoras, por meio do mecanismo de mutualismo direto dessas parcerias e do mutualismo indireto, legitimandoas como forma de organização empresarial. Os recém-chegados começaram, então, a competir, de certa maneira, com as grandes nos mercados nos países do centro. Os patentes benefícios econômicos das joint ventures e o aumento da legitimidade dessa estratégia, resultante do uso feito pelas grandes, criaram oportunidades para a proliferação de vários outros tipos de empresas que utilizavam esse mecanismo na indústria do alumínio. Os consórcios japoneses, em particular, tornaramse os mais importantes rivais das grandes, uma vez que as joint ventures feitas entre eles e empresas estatais em todo o mundo captaram muitas fontes de energia hidrelétrica a baixo custo, um recurso decisivo na produção de lingotes de alumínio.

Essas mudanças nas condições ambientais e competitivas, juntamente com a deteriorada capacidade competitiva das grandes, resultaram na mudança de estratégia de competição, feita por estas últimas durante a última década. As grandes pararam ou até mesmo reverteram o crescimento de sua capacidade de produção de alumínio, optando por voltar sua atenção para o final da cadeia de produção ou para outras indústrias. Essa erosão do domínio das grandes e de seu oligopólio criou um ambiente extremamente instável, especialmente para os preços de mercado para o alumínio em lingotes. A nova estrutura da indústria que surgiu nesse período de turbulência ambiental e competitiva é altamente competitiva e instável, com um aumento na freqüência de fusões, compras e falências. 
Para os recém-chegados à indústria global do alumínio, incluindo as empresas estatais brasileiras, venezuelanas e de outros países semiperiféricos, a perda do controle exercido pelo oligopólio das grandes sobre a capacidade de produção e sobre os preços significou que os investimentos feitos com base nas décadas anteriores de estabilidade enfrentavam, agora, um mercado e um futuro muito mais incertos. A terceira fase da globalização da indústria do alumínio, caracterizada por maciços investimentos, feitos por diversos tipos de empresas e governos nos países semiperiféricos, deixou um legado de turbulência e enormes dívidas externas para a quarta fase da globalização, ocorrida na década passada. Essa quarta fase inclui uma nova estratégia de desenvolvimento econômico para muitos países periféricos e semiperiféricos, uma reestruturação econômica, sendo também caracterizada pela privatização e pela retirada do poder público da economia. Os maciços investimentos feitos na mineração de bauxita, no refinamento de alumina, na fundição de alumínio e em muitas outras indústrias estão sendo transferidos a empresas nacionais e estrangeiras, a preços grandemente descontados.

Trata-se de uma importante oportunidade de investimento para muitas empresas de alumínio, mas também uma significativa perda econômica para os governos nacionais e uma abrupta perda de controle sobre o desenvolvimento social e econômico. 


\section{REFERÊNCIAS}

APPELBAUM, R., SMITH, D.; CHRISTERSON, B. Commodity chains and industrial restructuring in the Pacific rim: garment trade and manufacturing. In: GEREFFI, Gari; KORZENIEWICZ, Miguel (eds). Commodity chains and global capitalism. Westport, Conn.: Greenwood, 1994. p. 185-204.

AUTY, R. Resource-based industrialization: sowing the oil in eight developing countries. Nova Iorque: Oxford University Press, 1990.

BARHAM, B. L. Strategic capacity investments and the Alcoa-Alcan monopoly, 1888-1945. In: BARHAM, B., S. BUNKER S. G.; O'HEARN, D. (eds.). States, firms and raw materials. The world economy and ecology of aluminum. Madison, WI: University of Wisconsin Press, 1994.

BARHAM, B. L; BUNKER, S. G.; O'HEARN, D. Raw material industries in resource-rich regions. In: BARHAM, B., BUNKER S. G.; O'HEARN, D. (eds.). States, firms and raw materials. The world economy and ecology of aluminum. Madison, WI: University of Wisconsin Press, 1994.

. States, firms and raw materials. The world economy and ecology of aluminum. Madison, WI: University of Wisconsin Press, 1994.

BARNET, R.; MULLER, R. Global reach. Nova Iorque: Simon and Schuster, 1974.

BOWLES, Samuel; HERBERT Gintis. Efficient redistribution: new rules for markets, states and communities. In: WRIGHT, Erik Olin. Recasting egalitarianism: new rules for communities, states and markets, London: Verso, 1998.

BRUBAKER, S. Trends in the world aluminum industry. Baltimore: Johns Hopkins University Press, 1967.

BUNKER, S. G. Staples, links and poles in the construction of regional development theories. Sociological Forum, v. 4, n. 4, 1989, p. 589610 .

BUNKER, S. G.; CICCANTELL, P. The evolution of the world aluminum industry. In: BARHAM, B., S. BUNKER and D. O'HEARN (eds.). States, firms and raw materials. The world economy and ecology of aluminum. Madison, WI: University of Wisconsin Press, 1994. 
. Restructuring space, time, and competitive advantage in the capitalist world - system: Japan an raw materials transport after World War II. In: SMITH, D.; BOROCZ, J. (eds.) A new world order? Global transformations in the late 20th century. Westport, CT: Greenwood Press, 1995. p. 109-130.

CARR, C. Alcoa: an American enterprise. Nova Iorque: Rinehart and Company, 1952.

CHASE-DUNN, C. Global formation. Nova Iorque: Basil Blackwell, 1989.

CICCANTELL, P. Firms, states and raw materials in the capitalist world economy: aluminum and hydroelectricity in Brazil and Venezuela. Unpublished Ph.D. Dissertation: University of Wisconsin Madison, 1994b.

COGGINS, G.; WILKINSON, C. Federal public land and resources law. Nova Iorque: The Foundation Press, 1981.

COX, R. Corporate coalitions and industrial restructuring: explaining regional trade agreements. Competition and Change, v. 1,n.1, 1996. p. 13-30.

DAVIS, C. Jamaica in the world aluminium industry 1938-1939. Londres: Allen and Uwin, 1989.

EVANS, P. Dependent development: the alliance of multinational, state, and local capital in Brazil. Princeton: Princeton University Press, 1979.

FROBEL, F.; HEINRICHS, J.; KREYE, O. The new international division of labour. Cambridge: Cambridge University Press, 1980.

GIRVAN, N. Corporate imperialism: conflict and expropriation. Nova Iorque: Monthly Review Press, 1976.

GRAHAM, Margaret B. W.; PRUITT, Bettye H. RGD for industry: a century of technical innovation at Alcoa. Cambridge: Cambridge University Press, 1990.

GRAHAM, R. The aluminum industry and the Third World: multinational corporation and underdevelopment. London: Zed Press, 1982.

HARRISON, B. Lean and mean: the changing landscape of corporate power in the age of flexibility. New York: BasicBooks, 1994.

HIRSCHMAN, A. The strategy of economic development. New Haven: Yale University Press, 1958. 
HOLM, Hans-Henrik; SORENSON, Georg. Introduction: What Has Changed? In: HOLM, H.; SORENSON, G. (eds.) Whose world order? Uneven globalization and the end of the Cold War. Boulder, CO: Westview Press. 1995. p. 118.

HYMER, S. 1979. The multinational corporation: a radical approach. Cambridge: Cambridge University Press, 1979.

JENKINS, R. Transnational corporations and uneven development: the internationalization of capital and the Third World. London: Methuen, 1987.

MARLIO, L. The aluminum cartel. Washington: The Brookings Institution, 1947.

O'HEARN, D. 1994. Producing Imperialism anew: the United States, the United Kingdom, and Jamaican Bauxite. In: BARHAM, B., S. BUNKER and D. O'HEARN (eds.). States, firms, and raw materials: the world economy and ecology of aluminum. Madison, WI: University of Wisconsin Press, 1994. p. $147-178$

PECK, M. J. Competition in the Aluminum Industry, 1945-1958. Cambridge: Harvard University Press, 1961.

PERROUX, F. A note on the concept of growth poles. In: LIVINGSTONE, I. (ed.) Development economics and policy readings. Londres: George Allen G Unwin, 1955. p. 182-187.

PORTER, M. The competitive advantage of nations. Nova Iorque: The Free Press, 1990.

ROEMER, M. Resource-based industrialization in the developing countries. Cambridge: Harvard Institute for International Development, 1977.

SASSEN, S. The state and the global cCity: notes towards a conception of place-centered governance. Competition and Change, v. 1, n. 1, 1995. p. 31-50.

SMITH, G. From monopoly to competition: the transformations of Alcoa, 1888-1986. Cambridge: Cambridge University Press, 1988.

STEPHENS, E. H.; STEPHENS, J. Bauxite and democratic socialism in Jamaica. In: EVANS, Peter (ed.) States versus markets in the world-system. Beverly Hills: Sage. Strange, Susan. 1995. The Defective State. Daedalus, v. 124, n. 2, 1985. p. 55-75. 
STUCKEY, J. A. Vertical integration and joint ventures in the aluminum industry. Cambridge, Mass.: Harvard University Press, 1983.

WALLACE, D. Aluminum. In: ELLIOTT, W. et al. International control in the non-ferrous metals. Nova Iorque: The Macmillan Company, 1937.

WALLERSTEIN, I. The Modern World System. v.1 . Nova Iorque: Academic Press, 1974.

. The modern world system III: the second era of great expansi-

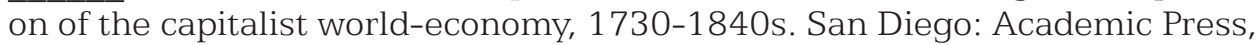
1989. 